\title{
1. Rapid urbanization and greenwashing in Asia
}

\section{Agatino Rizzo}

We are being told by leading scholars and Nobel Prize winners that we live in a new geological era called the Anthropocene (Crutzen and Stoermer, 2000). The Anthropocene is said to be that era that began with the Industrial Revolution of the nineteenth century and that until now has been dominated by what Andreas Malm has called the 'fossil capital' (Malm, 2016) - that is, the increased reliance on coal, oil, gas and other fossil by-products that literally fuel our economic growth. According to the leading scholars studying the Anthropocene, to end the ensuing global ecological disaster, a fundamental shift in technology towards low- or zero-carbon-based processes is required (Crutzen, 2006). The Anthropocene discourse is therefore inscribed within the wider narrative of sustainable development that began with the energy crisis of the 1970s (Mitchell, 2011).

This discourse has been challenged by social scientists who have criticized either the dichotomy of humanity/nature or the acritical technological take in which the Anthropocene concept is rooted. In the domain of environmental humanities, Moore (2016) challenges the Anthropocene discourse by arguing that nature and humanity cannot be abstractly separated. Moore argues that the biggest threat to planet Earth is the problematic relationship between capital and nature, what he also labels the 'cheap' exploitation of nature for endless capital accumulation (Moore, 2016, p. 89). This means that the ecological catastrophes befalling humanity are not the straightforward consequence of industrialization alone, but of the system that informs it - in brief, by capitalism.

On the other hand, Malm (2016) claims that fossil fuels are the main drivers of capitalism, being the enabling ingredient for endless cycles of expansion. The application of science in the form of new technologies, according to Malm, is geared to, at least in theory, an endless accumulation of wealth. However, in practice, the system we know as industrial capitalism, according to Sassen (2014) and Malm (2016), is grinding to a halt as new innovations are not able to lift the rates of return of capital investments, as used to happen. 
The above discourse is very relevant to urban studies and planning research. This is because research on sustainability and the development of technological improvements to manage climate change, also known as the smart city discourse, has taken the foreground of urban policy. The increasing popularity of 'green thought' (Moore, 2016) is, perhaps, the consequence of a deeper crisis in planning thought itself. Gleeson (2013) argues that as neo-liberal economic principles have gradually eroded critical urban scholarship, planners have shifted their attention from advocacy to more deterministic paradigms, those popular in the natural sciences. For example, the policy discourse on smart cities rests upon the idea of urban resilience - an umbrella theme that includes topics such as ecosystem services, low-carbon cities and so forth.

Resilience is, at its origins, an engineering concept that measures the ability of a system to return to its original state (of equilibrium) after a disturbance (Davoudi, 2012). ${ }^{1}$ In ecology, one of the scientific fields where the idea of resilience was applied earlier than in urban studies, resilience is defined as the amount of stress that a system can handle before moving to a different state of equilibrium (Holling, 1996). Both understandings of resilience depend on the concept of equilibrium - that is, the idea that a system hovers steadily around a specific status (Davoudi, 2012). Based on this idea, the concept of resilience has enjoyed popularity in the field of urban planning, and in particular in the areas of disaster management and climate adaptation (Gleeson, 2013). This growing multidisciplinary interest has facilitated the quick accumulation of knowledge and research on the green city topic but, interestingly, few studies have delved into the social impacts of green planning (e.g., the conditions of displacement and disempowerment of the rural communities), preferring more 'solid', hard facts (ibid.).

This utilitarian approach to resilience, which we would like to call 'green resilience', has gradually been incorporated into urban planning and has developed with concepts such as green-cities, infrastructure and urbanism (Caprotti, Springer and Harmer, 2015). ${ }^{2}$ Therefore, according to mainstream resilience literature, cities are supposed to capitalize on green infrastructure that can provide ecosystem services in order to support healthier lifestyles (e.g., walkability; Tzoulas et al., 2007), more resilient spaces in the face of ever more frequent natural disasters (e.g., flooding; Gill et al., 2007) or the mitigation of climate change impact on cities (e.g., urban heat islands; Young, 2011). However, the study of green infrastructure found in the planning literature emphasizes mostly the environmental, and often economic, performances (i.e., the utility of the ecosystem service) of non-urbanized areas rather than considering a more holistic approach to include societal issues. In their study of London's climate adaptation strategy, Davoudi, Brooks and Mehmood (2013) found that the emphasis of the plan for engineering resilience has prevented a more flexible and innovative approach to managing climate crises. The term 
'green resilience' has also been suggested by political scientist Carl Death (2014) in the context of South Africa to dissect different discourses on the green economy taking place there. As we are going to show in the following chapters, other studies have shown how the green development rhetoric has been deployed in some Asian megaprojects to disempower calls for regime change - that is, to increase democracy in policy, rather than fostering a more socially inclusive understanding of resilience (Crot, 2013; Cugurullo, 2016; Rizzo, 2017a).

\section{THE CASE STUDIES IN THIS BOOK}

Since the 1990s, emerging Asian economies have embarked on a massive modernization of their urban infrastructure, mostly through government-led, large-scale (or mega) projects (Rizzo, 2013). ${ }^{3}$ In this book, we will focus on state-orchestrated megaprojects in Qatar, Malaysia and India. This focus is justified by well-established trends in Asia that, in modern, urban development times, stretch back to the redevelopment of the city-state of Singapore and the extraordinary urban agenda of Dubai. Since then, the state-orchestrated large development or redevelopment type has both grown in size and been adopted by a number of emerging growth centres in the global South (Ouis, 2011). In Dubai alone, the megaproject model has been fully exploited to increase development opportunities for luxury resorts by the waters of the Persian Gulf (e.g., the Palm Trilogy, Dubai Marine, The World, The Universe islands and Hydropolis). This model has also been exported to other emirates of the Gulf, such as Abu Dhabi, Bahrain and Qatar. A number of researchers (Jackson and Della Dora, 2011; Ouis, 2011) have argued that the Gulf's megaprojects are the latest evolution of mega-gated communities that foster, at an unprecedented scale, social inequalities. However, while in the western world this 'secessionary space' (Graham and Marvin, 2001) is produced by the interplay of international real estate capital and planning and design consultancies (Rapoport and Hult, 2017), in the Gulf it is also funded directly or indirectly by the state. Therefore, it is important to pay attention to the displacements caused by state-funded megaprojects since they divert resources from other much-needed projects such as, for example, decent, affordable housing for low-income people (Petruccioli, 2015).

Arab countries in the Persian Gulf region are emerging as important economic and geopolitical hubs. ${ }^{4}$ As a result of these trends, over the last two decades, Gulf emirates have been able to attract a large number of low-skilled workers (labelled by the locals as 'labourers' or 'bachelors') as well as international knowledge workers (who are known by the locals as 'expats', an altogether more positive term). For example, in Doha, the capital of Qatar, between 2004 and 2013, the number of residents has tripled: overall, between 2004 and 
2013, the total population of Qatar rose from a humble 720000 inhabitants to 2.1 million (a threefold increase; World Bank Group, 2014). More than 80 per cent of the 2 million-plus people residing in Qatar and the 9 million in the United Arab Emirates (UAE) are immigrants, with the largest majority being low-paid workers from Asia (Mohammad and Sidaway, 2016; Rizzo, 2013). According to some unofficial estimates, Qataris account for 20 per cent of the total population, while South Asians and South East Asians account for 55 per cent; another 20 per cent are Arabs from other Middle East and North Africa (MENA) countries and 5 per cent are 'Others' (see Rizzo, 2017a). Also, due to foreign immigration, between 2004 and 2015, Doha's population increased from nearly 340000 to more than half a million inhabitants, while the Ministry of Municipality and Urban Planning (MMUP) forecasts that by 2032, Metro Doha (i.e., Doha and its satellite towns) will comprise 1.8 million inhabitants (Rizzo, 2013).

Several terms have been used to label the recent extraordinary urban growth of Arab capitals of the Persian Gulf (see Figure 1.1). For instance, Bagaeen (2007) has described Gulf cities in terms of their 'instant urbanism' to differentiate it from western, long-term urban evolution. Nearly three decades earlier, Riad (1981, p. 7) theorized a 'petro-urbanism' that 'undermined, with unparalleled suddenness, the roots of an ecosystem [the Gulf's] which reflected a perfect adaptation to an environment many generations old'. After independence from British protectorate rules in 1971, the state of Qatar embarked on a rapid phase of modernization on the strength of its rising oil revenues (Adham, 2008). During the 1970s, the American firm Pereira Architects shaped the new waterfront of Doha with the characteristic convex-like profile it maintains today. While, during the 1980s, the drop in oil prices slowed the pace of urban development, since the end of the 1990s, inspired by the success of Dubai, the state of Qatar has embarked in a vast state-funded megaproject campaign to globalize Doha and diversify its economy towards real estate, tourism and knowledge making (Rizzo, 2013). The American-style branch campus of Education City, the Qatar Science and Technology Park, the new Doha Financial Centre in West Bay, The Pearl (an offshore development modelled after Dubai's Palms), Losail City, the Hamad International Airport and the stadia for the 2022 FIFA World Cup are but a sampling of the large undertaking Qatar has embarked upon over the last 20 years.

Moving to the second case study, according to the Department of Statistics Malaysia (2010, pp. 11-12), Johor Bahru (JB) is a city of about half a million inhabitants (about 50 per cent of whom have a Chinese ethnic background, 40 per cent are Malays and 10 per cent are Tamil) located in the southern tip of Peninsular Malaysia (see Figure 1.2). It sits between two global cities: Kuala Lumpur (KL; 1.5 million inhabitants within the city and about 7 million if the adjacent regional commuting area is considered) ${ }^{5}$ and Singapore (5.7 million 


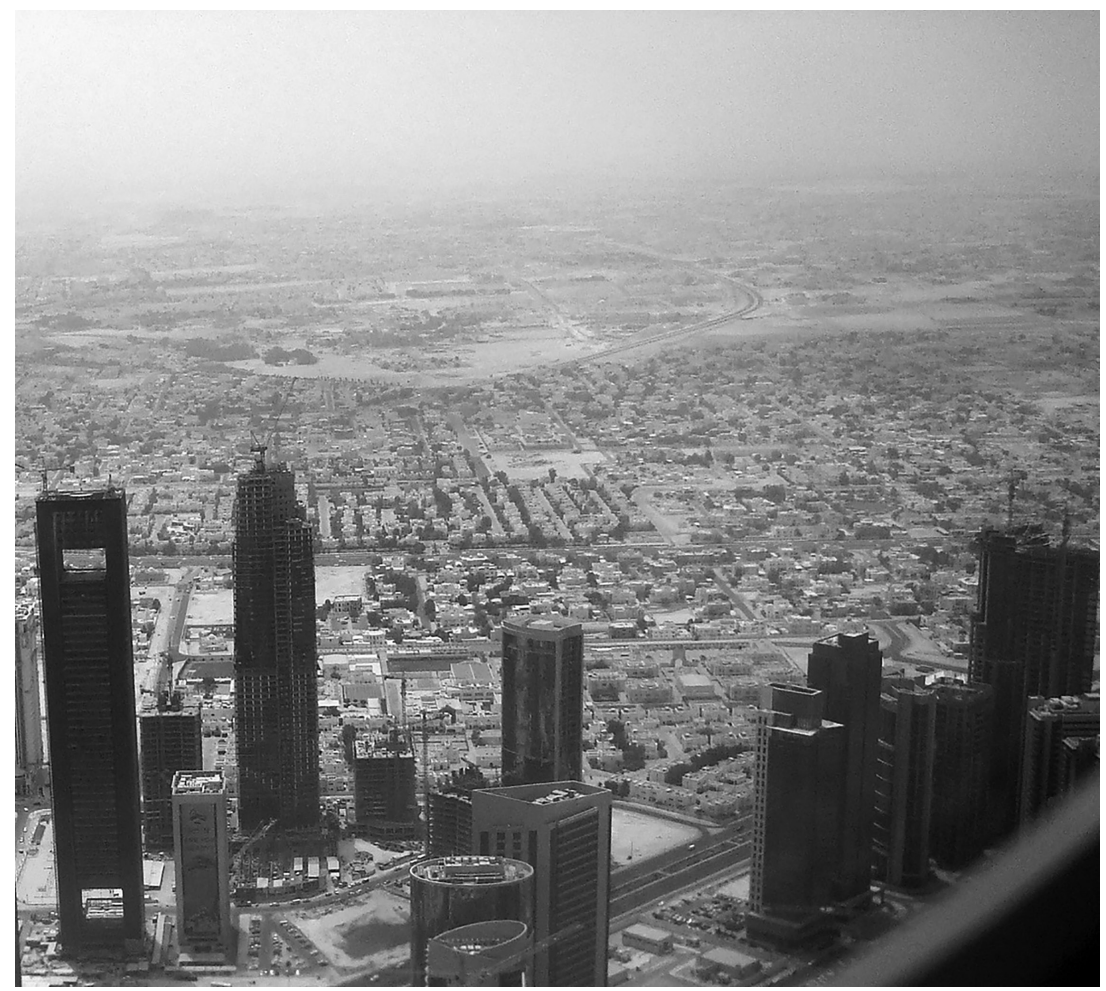

Source: Agatino Rizzo (2010).

\section{Figure 1.1 Doha: West Bay under construction}

inhabitants). ${ }^{6}$ Until 1957, both Malaysia and the city-state of Singapore were under the authority of the British Empire, which controlled the profitable trade route between China and Europe. While, on the one hand, JB is economically connected with its powerful neighbour, Singapore, on the other hand, it depends on the Malaysian state capital KL for leadership and financial resources. Moreover, the three cities are linked together by a network of infrastructures, services and small economic centres, which has led to theorization about the emergence of a Straits Megacity Region (Rizzo and Khan, 2013).

The JB metropolitan area is an industrial and commercial hotspot of Iskandar Malaysia (formerly the South Johor Economic Region [SJER]), boasting the presence of branches of a wide range of major commercial and industrial brands. JB's urban form reflects more spontaneity than planned regulated growth. ${ }^{7}$ Speculative and massive estates more than 15 storeys 


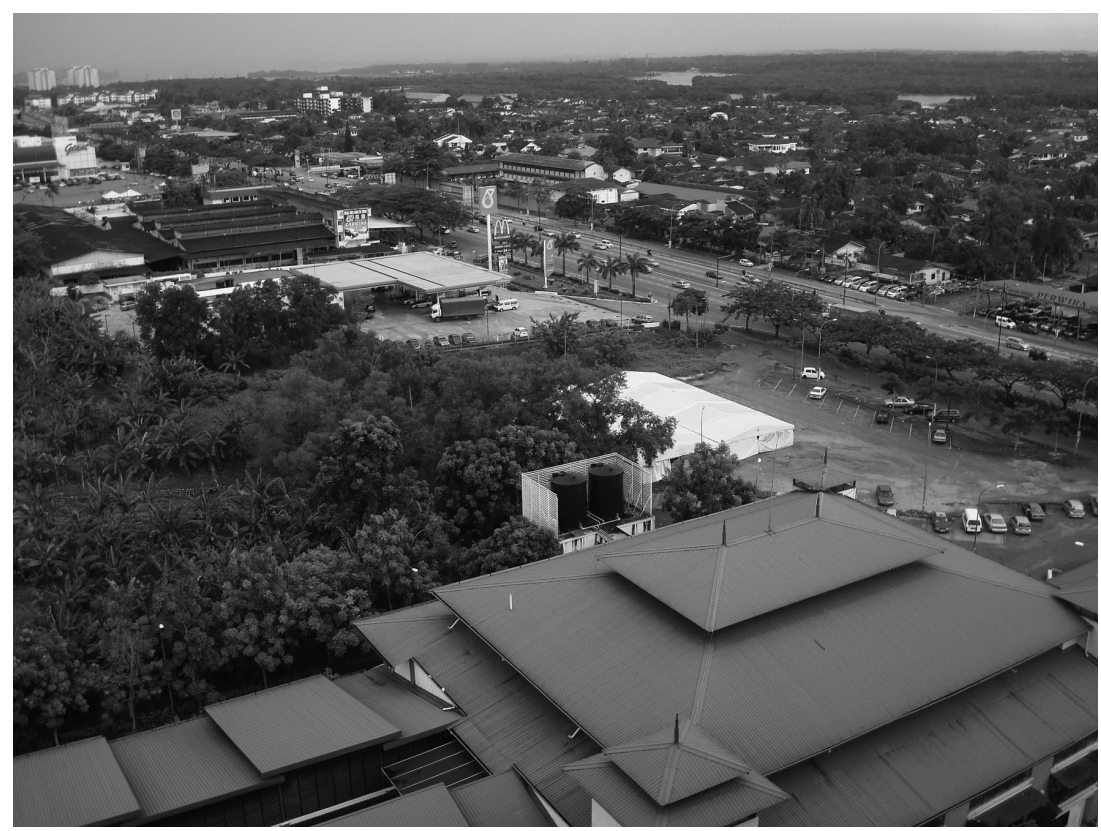

Source: $\quad$ Agatino Rizzo (2010).

\section{Figure 1.2 The urban landscape of Johor Bahru}

high mushroom randomly from a formerly low-rise built environment made up of linked houses and two- to three-storey buildings. From our elaborations, in 2010, the average population density was only 5.8 inhabitants per ha compared to neighbouring Singapore's almost 70. The Causeway, built during British colonial rule to link Singapore to the rest of Malaya in 1919, is a vital artery that connects JB to the global economic hub of Singapore by facilitating the transit of important volumes of people and freight. From our elaborations, about 15000 public transport commuters transit between JB and Singapore every day. As mentioned above, JB sits between two powerful regional hubs, KL and Singapore, the former its national capital and the latter its transnational neighbour. This reflects JB's natural locational advantage as a gateway between these two South East Asian global economic powerhouses. On the other hand, Barter (2006b) has highlighted the historical reasons and found evidence of JB's peripheral position against the rising centrality of the island-state Singapore that, according to him, has long since lost its 'islandness'. The centrality of KL in national policies and the quest to display the 
modernization of Malaysia has further compounded JB's position (Bunnell, Barter and Morshidi, 2002).

Moreover, JB could capitalize on the experience of the Multimedia Super Corridor (MSC) that was established in KL during the administration of the long-serving Prime Minister Mahathir Mohamad (who until recently was again filling the top post of Malaysian prime minister, supposedly covering for the now freed Anwar Ibrahim). As recounted by Bunnell (2004) in his study of the MSC, the corridor was one of the many examples of policy mobility, learning from Silicon Valley in California, USA to create what Castells and Hall (2014) call a 'technopole'. As we are going to see in this book, new cities, infrastructural corridors and megaprojects can be read in terms of state power rescaling to further cities' globalization and neo-liberal economic practices (Brenner, 2014; Bunnell, 2004). In this new ideological framework, territorial zones rather than entire nations are singled out for special economic incentives, legal exemptions and investment focus (Easterling, 2014). Both in KL

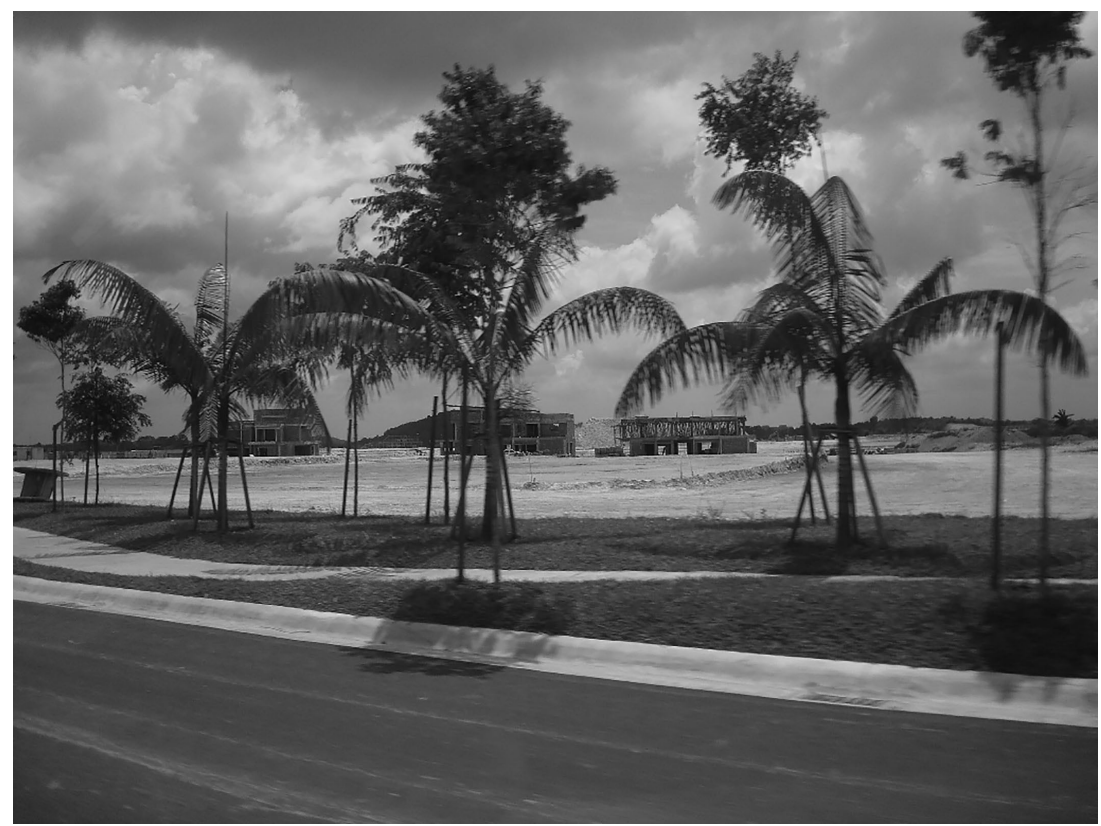

Source: $\quad$ Agatino Rizzo (2010).

Figure 1.3 View of Nusajaya (renamed Iskander Puteri in 2016), Johor Bahru after forest clearing near Horizon Hills development 
and $\mathrm{JB}$, the massive undertaking of building the corridors did not stop when confronted with the existence of existing plantations and farming communities (or kampong in Malay), which unfortunately for their inhabitants were in the way (Figure 1.3).

The third case study deals with large-scale redevelopment being planned in Mumbai, India. The city is a poignant example of the pressures many cities in developing countries face. Mumbai is the second largest of Asia's megacities and India's centre of finance and culture, which had been known to offer a high standard of living and employment opportunities for its residents. However, the natural increase in urban population, interregional migration and subsequent urbanization has been greater than the rate of infrastructural development for Mumbai. The need for brownfield redevelopment is highlighted by constrained land availability and congested living conditions. ${ }^{8}$ The physical need to provide more residential and commercial space for the increasing population along with the economic benefit derived from it has resulted in the favouring of urban intensification in Mumbai. The government is already providing an increased floor area ratio as an incentive to rebuild the city at a higher density than at present. The intensification is further supported by the recent World Conference 'Remaking Sustainable Cities in the Vertical Age', which highlighted the role of tall megaprojects in achieving higher density while also providing larger open spaces on the ground (such as parks and gardens) or improved infrastructure (such as roads) (Shivdasani, 2010).

However, it is not sufficient to provide housing without the supporting infrastructure. The current infrastructure is already under considerable strain, with power cuts and water shortages in many parts of the city. As cities become denser, they consume more resources and produce more waste within a confined area. When that area is itself constrained by physical boundaries, such as the Island City of Mumbai (although technically a peninsula), it becomes more dependent on the local infrastructure to provide resources and disperse waste. In an already dense city, it may be physically possible to increase floor area by building vertically (Bertaud, 2011). It may also be that this additional density is considered socially acceptable (Dave, 2010) and there may be advantages in additional open space. But in a resource-constrained city and an increasingly resource-constrained hinterland, the overriding concern becomes an environmental issue.

This case study follows the urbanization process of Mumbai through history, its subsequent need for infrastructural inputs and the resulting environmental impact. It then focuses on the present-day scenario, the proposed large-scale redevelopments in Mumbai that are likely to increase densities from about 3500 persons per hectare (ha) to about 5000, achieved by the demolition of existing three- to five-storey buildings and replacing them with 
towers averaging 40 floors - what has become known in Mumbai as 'vertical with a vengeance' (Rathod, 2012).

The case study investigates the impact of a proposed redevelopment of a 6.68-ha site by comparing the existing urban form with the proposed form. It uses the extended urban metabolism (Newman et al., 1996) model as a basis of analysis and predicts the flows of water supply (reticulated and rainwater harvesting), drainage, solid waste, electricity supply, potential for solar energy, fuel for transport, carbon dioxide production and sequestration. From the results of the 6.68-ha site, the analysis is then extrapolated to the overall impact if similar developments were to be carried out, as is proposed, across all of the Island City of Mumbai.

\section{DEFINING PREDATORY CITIES AND AIMS OF THE BOOK}

The Cambridge Dictionary defines 'predatory' as a 'person or organization [that] tries to get something that belongs to someone else'. ${ }^{10}$ In the Encyclopedia of Ecology (Minelli, 2008, p. 2923), 'predation' is defined as 'the ecological process by which energy is transferred from living animal to living animal based on the behavior of a predator that captures and kills a prey before eating it'. Thus, the term suggests a behaviour by which someone or something illegally or violently appropriates something else for its survival. Transferring this concept to the field of city studies, the act of tapping into remote resources (and images) is an old one in city making. Venice, for example, was built with wood and stones appropriated from the Balkans, while its cathedral was inspired by Byzantine equivalents of the Roman Empire in the East and decorated with statues stolen during the 'Sack of Constantinople' (in $1204 \mathrm{CE}$ ). The maritime powers of the Mediterranean Sea were propped up by a vast reserve of slaves (cheap human resources) who were employed in galleys or 'galere' (which is also the contemporary Italian term for jails). One can think of medieval city-states such as Venice as an assemblage of images and resources that stretched across the Mediterranean and well into Asia, the domain from which Venice extracted goods and resources that allowed its thriving economy to survive for centuries. A second interesting aspect of the definitions is that by preying on something else, the predator kills the object being hunted. This has an equivalent in both architecture and heritage studies as well as political ecology. For the former, one can draw parallels with the discussion about the 'patina' and authenticity developed by theorists such as Boito, Ruskin and Morris (Araoz, 2011; Wells, 2007), whereby a strong criticism towards French architect Viollet-le-Duc's doctrine of ideal, although fake, reconstruction of a building is formulated. For the latter, one can draw from the work of political ecologists such as Jason Moore (2016) about the 
cheap appropriation of nature in capitalist accumulation of wealth, and from urban theorists such as Saskia Sassen (2014) in her latest work on 'expulsions'.

In urban literature, there are only a few explicit uses of the adjective 'predatory' to describe planning strategies. ${ }^{11}$ One such example is Nagel and Nagel (2007). They are concerned with the expropriation of the commons in the context of planning for the reconstruction of New Orleans after Hurricane Katrina. In their view, '[when] planning decisions are made that result in the dispossession of the poor and privatization of land and public resources, the commons are sacrificed'. Therefore, 'predatory planning and the loss of the commons are inescapably linked' (Nagel and Nagel, 2007, p. 28). Going back over 30 years, one finds the term 'predator' being used by Buch (1988) to describe the problematic relationship between urbanization and its impacts on natural resources. Although misinterpreting the implications of the demographic projections on which he developed the discussion, Buch (1988, p. 129) correctly pointed to the importance of the nexus between urban growth and depletion of resources in terms of water, air and soil pollution. One drawback of his analysis is the limitation posed by the use of the national scale for analysing resource-draining processes that instead occur at multiple scales (Ward, 2010). Understanding resources within national boundaries fails to render the resource extraction process as a worldwide, North-South phenomenon (Bridge, 2008; Mitchell, 2011).

To be clear, in this book, we link the adjective 'predatory', which we use to describe the production and materiality of new master-planned cities, to the process of 'cheap resource exploitation'. ${ }^{12}$ The term predatory in our thinking should not suggest any relationship with a biological/mechanical, apolitical reading of the contemporary city - for example, the one that was so fashionable during the heydays of urban sanitation and public health movements in the beginning of the twentieth century (Scott, 2017). Our attempt is to leverage political ecology and a critical reading of urban metabolism to unpack the inherent contradictions of supposedly smart or eco-megaprojects and mega-redevelopments orchestrated by the neo-liberal state. Our theoretical stance is akin to that of critical urban theory, and within it, post-colonialism (Robinson, 2005) and city 'worlding' (Roy, 2009), while, at the same time, we draw from the work on relational urbanism and assemblages that has influenced our studies (Haarstad and Wanvik, 2017; Olds, 2002; Sigler, 2013). Here we will argue that the master-planning of new cities and the extensive redevelopment of existing ones in the booming global South implies both the access and cheap exploitation of a set of, on the one hand, intangible resources (e.g., architecture, images/models) and, on the other hand, tangible resources (both natural and human) that exceed the traditional local and even regional boundaries. Therefore, looking at these developments through the lens of the planning system only misses the fact that the construction of an entirely 
artificial new city implies access to a vast amount of natural (rocks, cement, marble etc.), human (international workers) and energy (gas, oil and, in the future, solar) resources that are sourced from elsewhere. Investigating the (predatory) logics of the resource-urbanization nexus allows the framing of mega-developments not as closed working sites within a specific country, but rather as hubs whose feeding resource network stretches locally, regionally and internationally (Robinson, 2005; Roy, 2009; Sigler, 2013).

Moore (2016) claims that a defining feature of capitalism is the 'cheap' appropriation of nature, understanding by this latter term not only natural resources but also exploited labour. ${ }^{13}$ At the same time, the extraction and transformation of Nature's resources (i.e., exploited human and natural resources; see Moore, 2016) in products or in transportable energy, alongside the extraction of labour from nearby and distant regions, have distinctive physical, ecological and social impacts (Bridge, 2008). The resource extraction economic model on which capitalism sits (Malm, 2016; Moore, 2016) is a waste-generating, primitive (although pervasive) model that evolves at the planetary scale - with several levels of interconnections between centres and peripheries worldwide. For example, in resource-rich regions, the cycles of urban growth and shrinking can be related to the volatile regime of commodity pricing that is set by both the market law of demand-supply and the strategic goals of the extractive industry (Mitchell, 2011). The space produced by the resource extraction economy is, at the same time, inhabited by people who are directly or indirectly affected by these processes. While the state should regulate this process, resource extraction is dominated by large private, publicly traded and state-owned corporations (e.g., oil companies, mining, energy utilities etc.) that have the ability, in the context of neo-liberalism, to influence policy and set the political agenda. Therefore, studying urbanization from the point of view of resources, what Rizzo (2019) has called the 'resourceurbanization nexus', requires at the same time a relational (multiple centresperipheries), translocal and multiscalar understanding of the political economy and ecology of those territories that, with various intensities, are conditioned by the extractive logic. While the term 'resource', particularly in the geographical context of the Middle East, is typically associated with oil and gas, in our work we enlarge its meaning to include any tangible and intangible factor of production that is aimed at capital accumulation - that is, labour, technology, natural resources and branding through the cheap appropriation of images. The branding of a city can also be related to a resource extraction process. Images from distant places, in both time and space, are often freely used in urban design to create the impression of being somewhere else. While there is a substantial body of academia that delves into the issue of architecture as a tool for tourism destination making (for the Gulf region see Henderson, 2006, 2014), more empirically one can notice that, in many of the megaprojects in Dubai 
or Singapore, there is almost always the feeling of being propelled to different places (Elsheshtawy, 2010). This is true whether walking the promenades of Dubai Marina thinking one is somewhere on France's Côte d'Azur, or taking a selfie in some of the venues along the Singapore River that are reminiscent of the waterfronts in North America (Chang, Huang and Savage, 2004).

In this book, we use the metaphor of 'predatory cities' to study rapid urbanization and megaprojects in Asia. Building on the available literature and our fieldwork observations, we will shine light on the processes that facilitate the emergence of state-orchestrated mega-developments and redevelopments and highlight their resource nexus. While a large body of studies has already analysed in depth the sustainability limitations of mega-developments from the social and environmental points of view (Crot, 2013; Jackson and Della Dora, 2009; Luomi, 2012; Mohammad and Sidaway, 2016; Moser, Swain and Alkhabbaz, 2015; Nagy, 2000; Olds, 2002; Ouis, 2011; Rizzo, 2014, 2017a, 2017b; Spiess, 2008), in this book we open a new front that we hope will expand the critique of neo-liberal new cities in the global South. Our point of departure is that the cheap appropriation and exploitation of resource networks for the making of new, master-planned cities is currently, in the eyes of city makers (the coalition of local planners, authorities, investors and international consultants), a necessary strategy to survive city competition, or - borrowing a term from biology, 'predation for survival' - is a key characteristic of new, master-planned cities in emerging Asian economies.

Though some social activists in Mumbai have voiced concerns over the impact of redevelopment and intensification on the availability of resources (such as water), managing output (like stormwater and sewage) and infrastructural capacity (such as vehicular congestion on roads), no formal study has been conducted to evaluate the impact of the proposed urban renewal at increased densities. In this case, we have compared the metabolic flows of existing development with potential redevelopment to quantify the infrastructural requirements and impact on the environment as a result of the intensification and change in built form that would accompany the urban renewal. The book qualitatively and quantitatively evaluates the urban drivers and patterns that impact the metabolism of neighbourhoods/clusters eligible for redevelopment and compares the change in metabolic flows between the existing and potential development by quantifying the impact of resources and outputs of wastes from the site and then analyses the potential benefits (if any) of the urban renewal process.

To analyse the case studies, we will leverage the urban metabolism framework as outlined above, as well as theories of megaprojects' displacements. Gellert and Lynch (2003) have studied several types of megaprojects, including 'extraction', 'infrastructure', 'production' and 'consumption', mega-developments that generate significant biogeophysical and social dis- 
placements. Biogeophysical and social displacements are thus at once an outcome of local neo-liberal urban policies and a tool to forcibly urbanize rural communities that are resistant to modernization (Goonewardena, 2014). While it is clear that the environmental impacts of megaprojects are an important factor around which to build a critique on green urbanism, social issues, on the other hand, are paramount to the understanding of the impact of global megaprojects on the local fabric of society in the global South. For example, scholars have lamented both the risk of losing the nations' identities (Chang et al., 2004) and the lack of governmental effort to capitalize on their increasing diversity. Furthermore, Gellert and Lynch (2003) distinguish between biogeophysical and social displacements to extract basic patterns that informed a critique of green urbanism/resilience. For them, biogeophysical displacements can be ascribed to large landscape modification that affects the balance of ecosystems, while the social displacements are the socio-political forces at work in such transformations. A further step in their methodology is the distinction between primary and secondary displacements: primary displacements refer to those impacts that can be foreseen and planned in advance, while secondary displacements pertain to those feedback loops that are more difficult to plan for.

Finally, in some of our case studies, resource appropriation extends to images and urban types that prey on well-known cities either from Islamic and non-Islamic polities of the Mediterranean region or from the West. For example, parts of, among others, Casablanca, Tunis, Saint-Tropez and Venice are conjured up in the different sections of Doha's Pearl island according to a unifying, master-planned vision of 'self-sustaining real estate development that includes all the amenities and lifestyle privileges any resident or guest could ask for'. ${ }^{14}$ The facades of the Porto Arabia neighbourhood and the bridges of the Qanat Quarter section work as gigantic urban stages behind which business-as-usual speculation logic dominates (Cugurullo, 2013) and in front of which audiences of international visitors enjoy spectacular (Elsheshtawy, 2010), if perhaps too easy to forget, experiences. This is perhaps one of the most striking differences between new megaprojects and the traditional city: the extreme and far-stretched reliance of the former on alien images of architecture and resource networks is what condemn them to be fragile and highly unsustainable visions.

\section{NOTES}

1. Excerpt from Rizzo, A. (2020). 'Megaprojects and the limits of "green resilience" in the global South: two cases from Malaysia and Qatar'. Urban Studies, 57(7), $1520-35$.

2. Ibid. 
3. Excerpt from Rizzo, A. (2019). 'Predatory cities: unravelling the consequences of resource-predatory projects in the global South'. Urban Geography, 40(1), 1-15.

4. Ibid.

5. Department of Statistics Malaysia (2020), accessed 9 March 2021 at https://www .dosm.gov.my/v1/index.php.

6. Statistics Singapore (2021). Population and population structure. Accessed 9 March 2021 at https://www.singstat.gov.sg/find-data/search-by-theme/population/ population-and-population-structure/latest-data.

7. Excerpt from Rizzo, A. and Khan, S. (2013). 'Johor Bahru's response to transnational and national influences in the emerging Straits Mega-City Region'. Habitat International, 40, 154-62.

8. In 2001, Greater Mumbai had a population of about 12 million, with an average household size of 4.62 (Mumbai Metropolitan Region Development Authority [MMRDA] Planning Team, 1996-2011b). Based on gross land area under residential use, the density is estimated to be $58000 / \mathrm{km}^{2}$ (Municipal Corporation of Greater Mumbai [MCGM], 2005-2025b). Households in Mumbai utilize an average of $2.9 \mathrm{~m}^{2}$ of floor space per person, which is one of the lowest residential floor areas per person in the world (Bertaud, 2004).

9. The conference was jointly organized by the Council on Tall Buildings and Urban Habitat (CTBUH) and the Remaking of Mumbai Federation (RoMF), held in Mumbai, 3-5 February 2010.

10. Excerpt from Rizzo, 'Predatory cities'.

11. Ibid.

12. Ibid.

13. Ibid.

14. Al Mana Services (2018). 'La Pearl Qatar'. Accessed 10 September 2020 at http:// landscaping.almana-services.com/Detail/23. 